\title{
(-)-Epigallocatechin-3-gallate induces apoptosis in gastric cancer cell lines by down-regulating survivin expression
}

\author{
CHIHIRO ONODA, KAGEAKI KURIBAYASHI, SHINYA NIRASAWA, \\ NAOKI TSUJI, MAKI TANAKA, DAISUKE KOBAYASHI and NAOKI WATANABE
}

Department of Clinical Laboratory Medicine, Sapporo Medical University School of Medicine, Sapporo 060-8543, Japan

Received November 11, 2010; Accepted January 4, 2011

DOI: 10.3892/ijo.2011.951

\begin{abstract}
The polyphenol (-)-epigallocatechin-3-gallate (EGCG) is a green tea constituent, which has been shown to inhibit cancer cell growth in vitro, in vivo and in epidemiological studies. In this study, we investigated its effects in gastric cancer cell lines. Five gastric cancer cell lines, the MKN-1, MKN-28, MKN-45, NUGC-3 and TMK-1, were found to be sensitive to EGCG treatment. Of all the cell lines tested, NUGC-3 was the most sensitive. EGCG treatment of NUGC-3 cells induced apoptosis, which was confirmed by sub-G1 analysis, caspase-Glo assay and Western blotting against cleaved PARP and cleaved caspase-3. EGCG treatment lowered survivin and increased Bax and TRAIL expression. Furthermore, EGCG induced p73 activation in NUGC-3 cells. Small interfering RNA against p73 diminished EGCG effects on survivin expression and cell viability. These results show that EGCG induces cell death in gastric cancer cells by apoptosis via inhibition of survivin expression downstream of p73. This study provides a novel mechanism whereby EGCG potentially inhibits cancer cell growth, concluding that EGCG may be a potential candidate in anti-survivin cancer therapy.
\end{abstract}

\section{Introduction}

Tea, which is derived from the leaves of the plant Camellia sinensis is the world's most widely consumed beverage, next to water. Components of green tea are well characterized and have been studied for their beneficial effects, including antihypertensive effects, body-weight regulation, antibacterial

Correspondence to: Dr Naoki Watanabe, Department of Clinical Laboratory Medicine, Sapporo Medical University School of Medicine, South-1, West-16, Chuo-ku, Sapporo 060-8543, Japan

E-mail: watanabn@sapmed.ac.jp

Abbreviations: EGCG, (-)-epigallocatechin-3-gallate; FBS, fetal bovine serum; NF- $\kappa \mathrm{B}$, nuclear factor- $\kappa \mathrm{B}$; RT-PCR, reverse-transcriptase polymerase chain-reaction

Key words: apoptosis, survivin, p73, (-)-epigallocatechin-3-gallate, gastric cancer activity, solar ultraviolet protection, osteal mineral density enhancement, anti-fibrotic properties, neuroprotective effects, and cancer chemoprevention (1). Many studies have shown that green-tea consumption inversely correlates with prevalence of various types of cancers, including colonic, pulmonary, gastric, esophageal, mammary, prostatic, ovarian, and pancreatic cancers (2).

Recent studies have revealed that (-)-epigallocatechin-3gallate (EGCG), a major polyphenol in green tea, mediates its anti-cancer effects. EGCG inhibits gastric cancer formation induced by $\mathrm{N}$-methyl-N'-nitro-N-nitrosoguanidine in rats (3). EGCG was shown to reduce the number of tumors in $\mathrm{A} / \mathrm{J}$ mice with cisplatin-induced lung tumors (4). EGCG administration inhibits formation of spontaneous intestinal tumors in $\mathrm{APC}^{\mathrm{min} /+}$ mice (5).

Reportedly, EGCG suppresses growth of cancer cells by inhibiting the nuclear factor- $\mathrm{B}(\mathrm{NF}-\kappa \mathrm{B})(6)$ and Akt pathways (7), and by activating the p53 (8) and p73 pathways (9). The fascinating advantage of EGCG as a chemopreventive agent lies in its ability to eliminate transformed or neoplastic cells selectively, while sparing, or in some cases, protecting normal cells. This selectivity may result from EGCG's ability to target abnormal cell-signaling or anti-apoptotic proteins specifically in tumor cells (10).

Survivin is a multifunctional protein that belongs to inhibitor of apoptosis protein family and regulates apoptosis and many other phenomena beneficial to cancer cells (11). For example, survivin not only inhibits apoptosis and protects cancer cells against various cytotoxic factors, but also confers immortalization and immune privilege to them by up-regulating human telomerase reverse transcriptase and Fas ligand, respectively $(12,13)$. Elevated survivin expression is observed in various types of human malignancies, including pulmonary (14), mammary $(15,16)$, esophageal $(17)$, gastric $(18,19)$, colonic $(13,20,21)$, pancreatic $(22)$, hepatic (23), uterine (24), and ovarian cancers $(25)$ as well as in leukemia $(26,27)$. Survivin is an attractive target for cancer therapeutics because it is overexpressed in transformed cells, but not in normal cells. As EGCG exerts its anti-proliferative effect selectively on cancer cells, we hypothesized that survivin may be a molecular target of EGCG.

In this study, we demonstrate that EGCG induces apoptosis in gastric cancer cell lines by down-regulating survivin expression downstream of p73 activation. 


\section{Materials and methods}

Cell culture. Human gastric cancer cell lines MKN-1, MKN-28, MKN-45, and TMK-1-were purchased from the American Type Culture Collection (Manassas, VA). NUGC-3 was obtained from the Japanese Collection of Research Bioresources (Osaka, Japan). These cell lines were cultured in RPMI-1640 (Lonza, Tokyo, Japan) supplemented with 10\% heat-inactivated fetal bovine serum (FBS; Hyclone, Yokohama, Japan) and grown at $37^{\circ} \mathrm{C}$ in a humidified atmosphere of $5 \%$ $\mathrm{CO}_{2}$.

Reagents. EGCG was obtained from Sigma-Aldrich (St. Louis, $\mathrm{MO}$ ) and dissolved in dimethyl sulfoxide (DMSO). Anti-Bcl-2, anti-Bcl-XL, anti-cFLIP, and anti-actin antibodies were purchased from Santa Cruz Biotechnology (Santa Cruz, CA). Anti-survivin, anti-XIAP, anti-cIAP-1, and anti-cIAP-2 antibodies were purchased from R\&D Systems (Minneapolis, MN). Anti-cleaved caspase-3, anti-Akt, anti-phospho-Akt, and anti-PARP antibodies were purchased from Cell Signaling Technology (Danvers, MA). Anti-Ran antibody was purchased from BD Biosciences Pharmingen (San Jose, CA). Anti-p73 antibody (GC-15) was purchased from EMD Chemicals (Gibbstown, NJ).

Measurement of cell viability. Cells were plated in 96-well plates at a density of 5,000 cells per well in RPMI supplemented with $10 \%$ FBS. The cells were allowed to adhere for $24 \mathrm{~h}$ and were subjected to Cell Titer-Glo ${ }^{\mathrm{TM}}$ Luminescent Cell Viability Assay (Promega, Madison, WI) according to the manufacturer's instructions. The level of ATP-drived luminescent signal, which correlates with the number of viable cells, was measured using Veritas $^{\mathrm{TM}}$ Microplate Luminometer (Promega).

Sub-G1 analysis. After the treatments indicated in the figure, the cells were washed with phosphate-buffered saline, re-suspended in $500 \mu 1$ of hypotonic fluorochrome solution $(50 \mu \mathrm{g} / \mathrm{ml}$ propidium iodide in $0.1 \%$ sodium citrate, $0.1 \%$ Triton $\mathrm{X}-100$ ) and incubated at room temperature for $30 \mathrm{~min}$ in the dark. A flow cytometer (EPICS XL-MCL cytometer, Beckman Coulter, Tokyo, Japan) was used to measure 20,000 events per sample.

Measurement of caspase-3/ and -7 activities. Caspase- 3 and -7, activities were measured using Caspase-Glo 3/7 Assay (Promega). Five thousand cells were seeded in 96-well plates in $100 \mu 1$ RPMI-1640 supplemented with 10\% FBS and incubated for $24 \mathrm{~h}$. Cells were treated with $100 \mu \mathrm{M}$ EGCG and incubated for another $24 \mathrm{~h}$. One hundred $\mu \mathrm{l}$ of assay reagent was added to each well and incubated for $1 \mathrm{~h}$ at room temperature. Luminescence was measured using a Veritas Microplate Luminometer.

Western blotting. After various treatments as indicated in the figures, cells were harvested in a lysis buffer $(50 \mathrm{mM}$ Tris- $\mathrm{HCl}$, $\mathrm{pH}$ 8.0, $150 \mathrm{mM} \mathrm{NaCl}, 5 \mathrm{mM}$ EDTA) with protease inhibitor cocktail (Sigma-Aldrich) sonicated for $30 \mathrm{sec}$, and centrifuged at $15,000 \mathrm{rpm}$ for $5 \mathrm{~min}$. The supernatants were mixed with equal volume of Laemmli sample buffer, boiled for $2 \mathrm{~min}$, and separated on a 4-20\% Tris-glycine gradient gel (Invitrogen,
Carlsbad, CA) under denaturing conditions. The proteins were electroblotted onto a nitrocellulose membrane and detected by WesternBreeze chemiluminescent immunodetection kit (Invitrogen) according to the manufacturer's instructions. The bands were visualized and imaged using ChemiDoc XRS Plus (Bio-Rad, Hercules, CA).

Quantification of BIRC5 (survivin) mRNA. Expression of BIRC5 (survivin) mRNA was determined by quantitative reverse-transcriptase polymerase chain-reaction (RT-PCR) using the ABI PRISM 7700 sequence-detector system (Applied Biosystems, Foster City, CA). Total RNA was isolated using the RNeasy Plus Mini kit (Qiagen, Valencia, CA) according to the manufacturer's instructions. The cDNA was reversetranscribed by Taqman Reverse-Transcription Reagents (Applied Biosystems, Branchburg, NJ). The gene-specific primers and fluorescent hybridization probes for survivin were as follows: For BIRC5 mRNA: 5'-AAGAACTGGCCCTTCTTGGA-3', 5'-CAACCGGACGAATGCTTTT-3', and 5'-(FAM)CCAGAT GACGACCCCATAGAGGAACA (TAMRA)-3' were used as forward primer, reverse primer, and the TaqMan probe, respectively.

Silencing of $p 73$. NUGC-3 cells were cultured in 6-well plates and transfected with 50 pmol of siRNA against TP73 or non-silencing control siRNA using the TransPass R1 transfection reagent (New England Biolabs, Ipswich, MA) according to the manufacturer's instructions. Double stranded siRNAs were synthesized by, and purchased from, Sigma-Aldrich, Japan (Ishikari, Japan). The sequence of siRNA against TP73 is 5'-CCUUAGAGGACUGGAAAUU-3'.

\section{Results}

EGCG induces apoptosis in gastric cancer cell lines. First, we tested the effect of EGCG on cell viability in gastric cancer cell lines. As shown in Fig. 1, EGCG suppressed the growth of the cancer cell lines in a dose-dependent manner. To find out the mechanism whereby EGCG affected cell viability, we performed cell-cycle analysis using NUGC-3 cells, the most EGCG-sensitive cell line tested in this study. As shown in Fig. 2A, EGCG increased sub-G1 cell population while there was no apparent effect on the cell cycle. EGCG increased caspase-3/-7 activity (Fig. 2B) and induced cleavage of PARP and caspase-3 (Fig. 2C). These results show that EGCG induces apoptosis in NUGC-3.

EGCG suppresses survivin expression. We next screened for molecules associated with the apoptotic pathway, which potentially underlies the cell death induced by EGCG. Bax and TRAIL expression increased after EGCG treatment (data not shown). Among various anti-apoptotic molecules, survivin expression was down-regulated after EGCG treatment (Fig. 3A). EGCG suppressed survivin expression in a time(Fig. 3B) and dose-dependent manner (Fig. 3C). Except for MKN-1 cells, suppression of survivin expression was also seen in other gastric cancer cell lines (Fig. 4). We next assessed whether survivin suppression occurs at the mRNA level. As shown in Fig. 5, EGCG treatment suppressed BIRC5 mRNA in a time-dependent manner. 

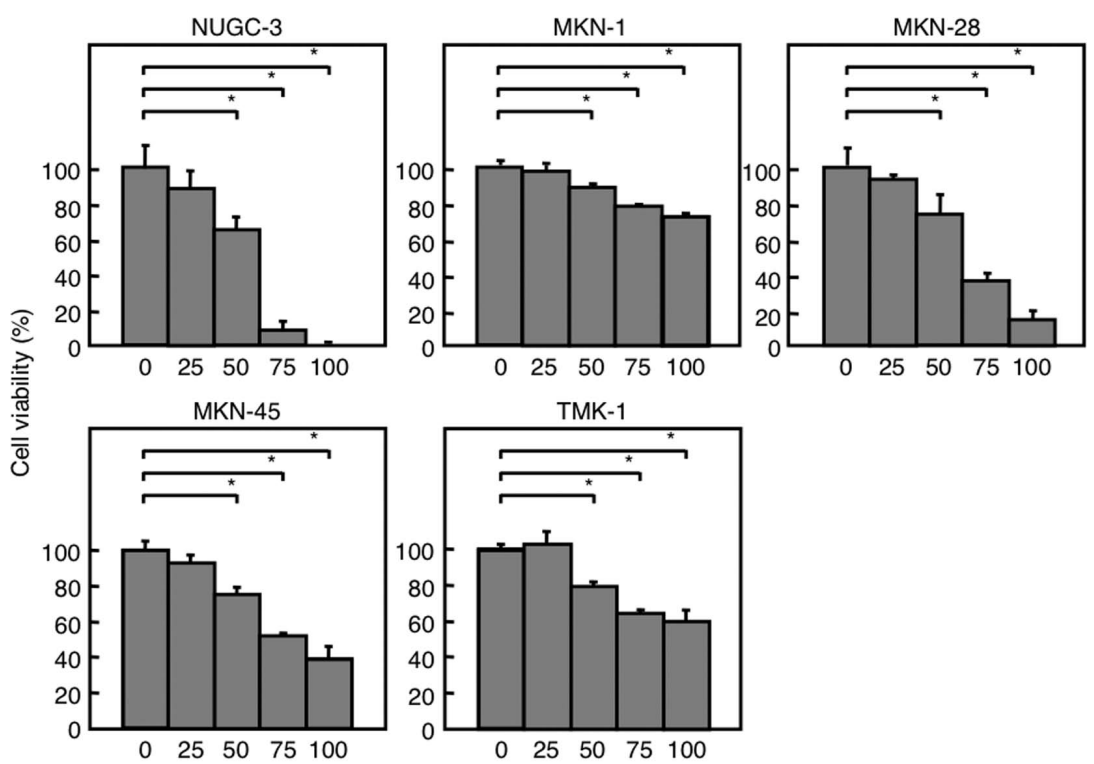

EGCG concentration $(\mu \mathrm{M})$

Figure 1. EGCG inhibits growth of gastric cancer cell lines. Cells were treated with different concentrations of EGCG for $24 \mathrm{~h}$ and cell viability was measured by an ATP assay as described in Materials and methods. "Indicates statistical significance at $\mathrm{p}<0.01$.

A

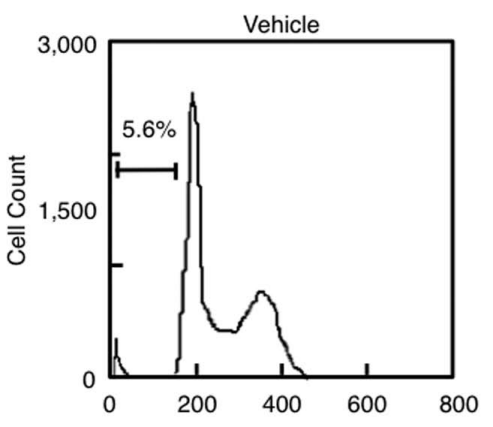

B

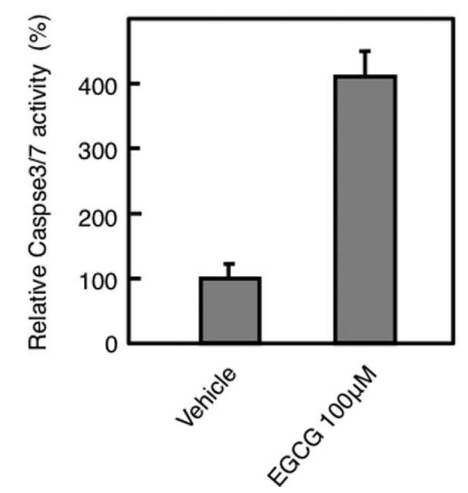

EGCG $100 \mu \mathrm{M}$

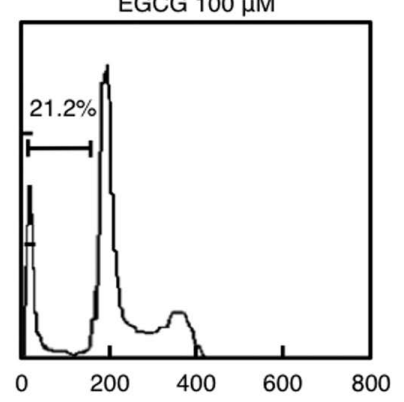

C

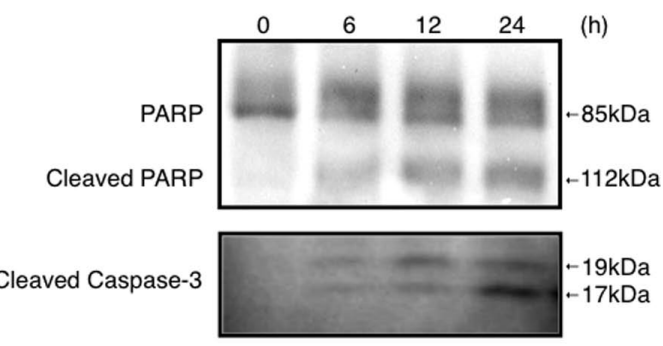

Ran

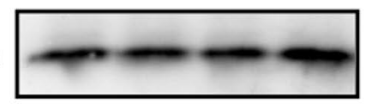

Figure 2. EGCG induces apoptosis in NUGC-3 gastric cancer cell line. NUGC-3 was treated with or without $100 \mu \mathrm{M}$ EGCG for $24 \mathrm{~h}$ and samples were subjected to sub-G1 analysis (A) or caspase-3/-7 activity measurement (B), respectively, as described in Materials and methods. (C) NUGC-3 was treated with $100 \mu \mathrm{M}$ EGCG for different times indicated in the figure and subjected to Western blotting.

Survivin suppression induced by EGCG is regulated by $p 73$. Survivin, Bax, and TRAIL are transcriptionally regulated by p53 $(28,29)$. However, the cell lines we used in this study involve a TP53 wild-type line (MKN-45) and four TP53mutated lines (NUGC-3, MKN-1, MKN-28, and TMK-1). Because all the cell lines decreased survivin, we hypothesized that p73, a p53 family member, may be regulating expression of these molecules following EGCG-induced p73 activation. As shown in Fig. 6A, EGCG activated p73 in a time-dependent manner up to $12 \mathrm{~h}$.

We next examined whether survivin is downstream of p73. We silenced p73 expression by siRNA against TP73 and treated the cells with or without EGCG. As shown in Fig. 6B, EGCG treatment suppressed expression of survivin in cells 
A

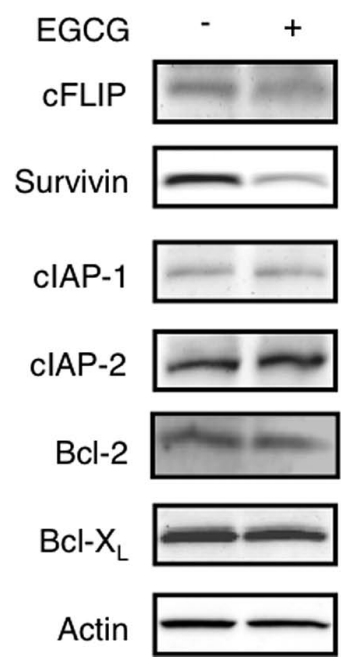

B

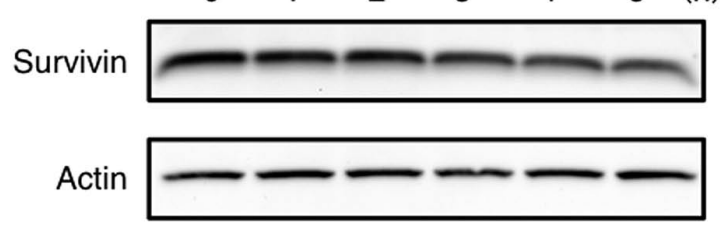

C

EGCG $(\mu \mathrm{M})$

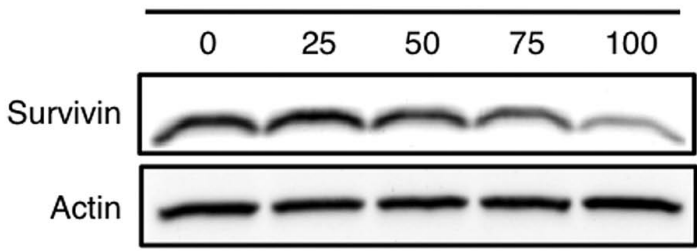

Figure 3. EGCG reduces survivin expression. (A) NUGC-3 was treated with or without $100 \mu \mathrm{M}$ EGCG for $6 \mathrm{~h}$ and samples were subjected to Western blot analysis. The blots were developed using antibodies indicated in the figure. (B) NUGC-3 was treated with $100 \mu \mathrm{M}$ EGCG as indicated in the figure and subjected to Western blot analysis. (C) NUGC-3 was treated with different concentrations of EGCG for $5 \mathrm{~h}$ and subjected to Western blotting.

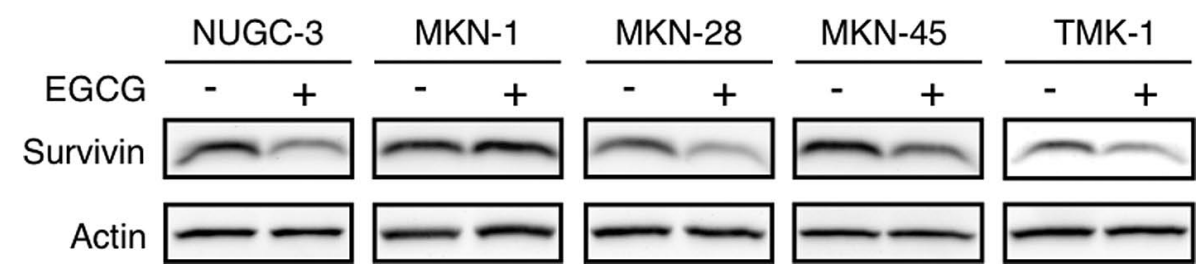

Figure 4. EGCG reduces survivin expression in gastric cancer cell lines. Gastric cancer cell lines were treated with $100 \mu \mathrm{M}$ EGCG for $6 \mathrm{~h}$ and subjected to Western blot analysis using antibodies indicated in the figure.

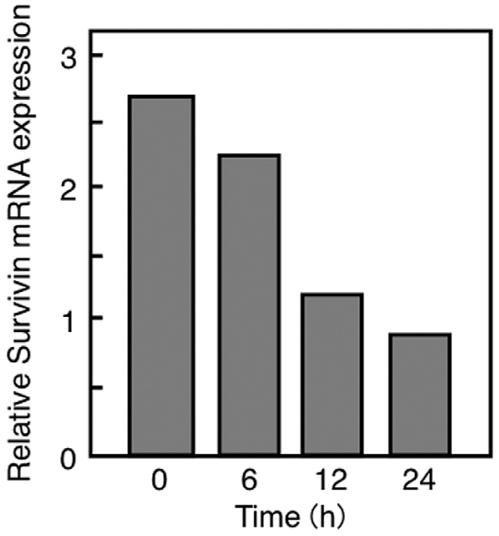

Figure 5. EGCG inhibits survivin mRNA expression. NUGC-3 cells were treated with $100 \mu \mathrm{M}$ EGCG as indicated in the figure and BIRC5 (survivin) mRNA levels were measured by Taqman RT-PCR as described in Materials and methods. The ratios of BIRC5 mRNA against the level of $18 \mathrm{~S}$ rRNA are given as bar graphs.

transfected with non-silencing siRNA, whereas EGCG did not suppress survivin expression in cells transfected with siRNA against $T P 73$. These results show that EGCG-induced survivin suppression is regulated by $\mathrm{p} 73$. p73 silencing confers resistance to EGCG. We next examined whether p73 silencing affects cell viability in NUGC-3 cells. As shown in Fig. 6C, EGCG suppressed the growth of NUGC-3 cells transfected with control siRNA, whereas this effect was antagonized by the transfection of siRNA against TP73. This result shows that the suppression of cell growth induced by EGCG is mediated by the p73 pathway.

\section{Discussion}

In this study, we showed that EGCG induces apoptosis in gastric cancer cell lines by down-regulating survivin through p73 activation.

Survivin is an attractive molecular target in cancer therapeutics as it is overexpressed in transformed cells but not in normal tissue. Besides BIRC5 gene-targeting therapy, smallmolecule inhibitors of survivin expression are under investigation in this context (30). There are several mechanisms whereby small molecules inhibit survivin expression in cancer cells. Inhibition of cyclin-dependent kinases by purvalanol A and NU6140 down-regulates survivin expression and leads to apoptosis in MCF7, PC 3, and HeLa cells $(31,32)$. Tetra-O-methyl nordihydroguaiaretic acid induces cell-growth arrest and apoptosis by inhibiting Cdc2 and survivin expression in an 
A

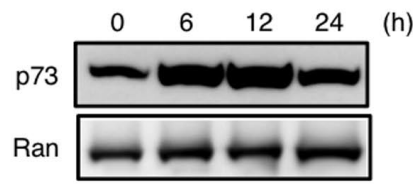

B

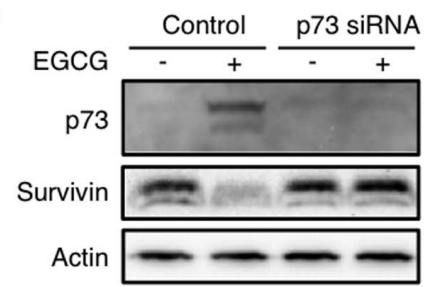

C

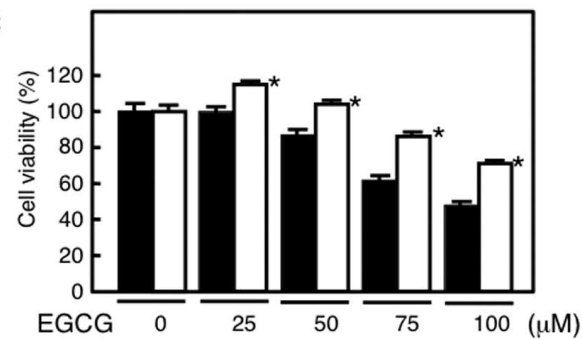

D

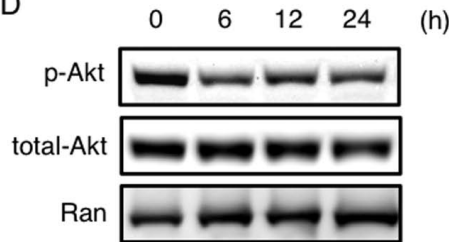

E

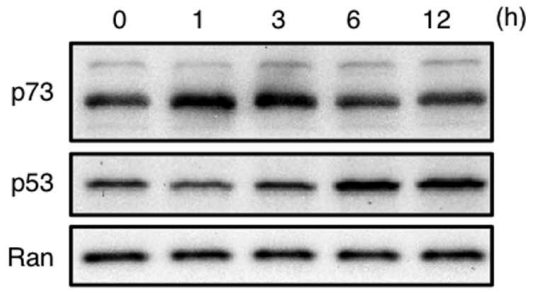

Figure 6. TP73 siRNA inhibits survivin down-regulation. (A) NUGC-3 cells were treated with EGCG for various durations as indicated in the figure and subjected to Western blot analysis. (B) NUGC-3 cells were transfected with siRNA against TP73 or with the non-silencing control RNA, treated with or without $100 \mu \mathrm{M}$ EGCG for $6 \mathrm{~h}$, and subjected to Western blot analysis. (C) NUGC-3 cells were transfected with siRNA against TP73 ( $\square$ ) or with the nonsilencing control RNA (ם), treated with various levels of EGCG for $6 \mathrm{~h}$ as indicated in the figure, and cell viability was measured as described under Materials and methods. (D) NUGC-3 cells were treated with $100 \mu \mathrm{M}$ EGCG for the times indicated in the figure and subjected to Western blot analysis. (E) MKN45 gastric cancer cell line, which has wild-type p53, was treated with EGCG for the times indicated in the figure and subjected to Western blot analysis.

Sp-1-dependent manner (33). Shepherdin interferes with Hsp90 chaperone activity thereby repressing expression of its target protein, survivin, and induces cell death in transformed cells but not in normal cells (34). We and others have shown that inhibition of the Ras and Akt pathway suppresses survivin expression (35-37). p73 activation found in this study, is a novel mechanism for targeting survivin in cancer cells.

Recently, Tang et al reported that EGCG inhibits the Akt pathway and decreases BIRC5 mRNA expression, which results in apoptosis of breast cancer cell lines (36). In this study, we have confirmed that the Akt pathway is also inhibited by EGCG (Fig. 6D). Together with activation of the 73 pathway, EGCGdriven inhibition of Akt pathway may lead to suppression of survivin expression in gastric cancer cell lines. NF- $\mathrm{KB}$ activation leads to enhanced expression of anti-apoptotic proteins, including Bcl-XL, BCL-2, and cIAPs (38). In this study, we could not observe whether EGCG affected expression of these proteins. These observations suggest that the NF-кB pathway may not be targeted by EGCG in gastric cancer cell lines.

Activation of p73 by EGCG is fascinating because TP73 mutation is an infrequent event in cancers (39). How EGCG activates p73 is an open question. To address this issue, we stimulated the MKN-45 gastric cancer cell line, which harbors wild-type p53, and analyzed the time course of p53 and p73 activation. As shown in Fig. 6E, p73 activation kinetics was different, but rather reciprocal, from that of $\mathrm{p} 53$, suggesting that distinct mechanisms may underlie EGCG-induced p53 and $\mathrm{p} 73$ activation. Two reports show that $\mathrm{p} 73$ is activated by EGCG $(9,40)$. One of these studies showed that reactive oxygen species produced by EGCG is the factor that activates p73 (9). Elucidation of this mechanism is one of our future goals.

It is not clear how p73 inhibits survivin expression. There are p53-binding sequences in the BIRC5 promoter region, and wild-type p53 was shown to repress BIRC5 translation $(41,42)$. Because p73 can transactivate reporter genes containing consensus p53-binding sites as well as traditional p53 target genes (43), a similar mechanism may be regulating BIRC5 expression by $\mathrm{p} 73$.

In conclusion, here we described a target molecule and a novel pathway, which attenuate survivin expression. EGCG can be a potential tool in the treatment of gastric cancers.

\section{Acknowledgements}

The first two authors contributed equally. There is no potential financial or personal conflict of interest to disclose.

\section{References}

1. Cabrera C, Artacho R and Gimenez R: Beneficial effects of green tea-a review. J Am Coll Nutr 25: 79-99, 2006.

2. Yang CS, Wang X, Lu G and Picinich SC: Cancer prevention by tea: animal studies, molecular mechanisms and human relevance. Nat Rev Cancer 9: 429-439, 2009.

3. Yamane T, Takahashi T, Kuwata K, et al: Inhibition of N-methylN'-nitro-N-nitrosoguanidine-induced carcinogenesis by (-)-epigallocatechin gallate in the rat glandular stomach. Cancer Res 55: 2081-2084, 1995.

4. Mimoto J, Kiura K, Matsuo K, et al: (-)-Epigallocatechin gallate can prevent cisplatin-induced lung tumorigenesis in $\mathrm{A} / \mathrm{J}$ mice. Carcinogenesis 21: 915-919, 2000. 
5. Ju J, Hong J, Zhou JN, et al: Inhibition of intestinal tumorigenesis in Apcmin/+ mice by (-)-epigallocatechin-3-gallate, the major catechin in green tea. Cancer Res 65: 10623-10631, 2005.

6. Ahmad N, Gupta S and Mukhtar H: Green tea polyphenol epigallocatechin-3-gallate differentially modulates nuclear factor kappaB in cancer cells versus normal cells. Arch Biochem Biophys 376: 338-346, 2000.

7. Sah JF, Balasubramanian S, Eckert RL and Rorke EA: Epigallocatechin-3-gallate inhibits epidermal growth factor receptor signaling pathway. Evidence for direct inhibition of ERK1/2 and AKT kinases. J Biol Chem 279: 12755-12762, 2004.

8. Hastak K, Gupta S, Ahmad N, Agarwal MK, Agarwal ML and Mukhtar H: Role of p53 and NF-kappaB in epigallocatechin3 -gallate-induced apoptosis of LNCaP cells. Oncogene 22: 4851-4859, 2003

9. Amin AR, Thakur VS, Paul RK, et al: SHP-2 tyrosine phosphatase inhibits p73-dependent apoptosis and expression of a subset of p53 target genes induced by EGCG. Proc Natl Acad Sci USA 104: 5419-5424, 2007.

10. Ahmad N, Feyes DK, Nieminen AL, Agarwal R and Mukhtar H: Green tea constituent epigallocatechin-3-gallate and induction of apoptosis and cell cycle arrest in human carcinoma cells. J Natl Cancer Inst 89: 1881-1886, 1997.

11. Altieri DC: Survivin, versatile modulation of cell division and apoptosis in cancer. Oncogene 22: 8581-8589, 2003.

12. Asanuma K, Tsuji N, Endoh T, Yagihashi A and Watanabe N: Survivin enhances Fas ligand expression via up-regulation of specificity protein 1-mediated gene transcription in colon cancer cells. J Immunol 172: 3922-3929, 2004

13. Endoh T, Tsuji N, Asanuma K, Yagihashi A and Watanabe N: Survivin enhances telomerase activity via up-regulation of specificity protein 1- and c-Myc-mediated human telomerase reverse transcriptase gene transcription. Exp Cell Res 305: 300-311, 2005

14. Tanabe H, Yagihashi A, Tsuji N, Shijubo Y, Abe S and Watanabe N: Expression of survivin mRNA and livin mRNA in non-small-cell lung cancer. Lung Cancer 46: 299-304, 2004.

15. Tanaka K, Iwamoto S, Gon G, Nohara T, Iwamoto M and Tanigawa N: Expression of survivin and its relationship to loss of apoptosis in breast carcinomas. Clin Cancer Res 6: 127-134, 2000.

16. Tsuji N, Furuse K, Asanuma K, et al: Mutations of the p53 gene and loss of heterozygosity at chromosome $17 \mathrm{p} 13.1$ are associated with increased survivin expression in breast cancer. Breast Cancer Res Treat 87: 23-31, 2004.

17. Kato J, Kuwabara Y, Mitani M, et al: Expression of survivin in esophageal cancer: correlation with the prognosis and response to chemotherapy. Int J Cancer 95: 92-95, 2001.

18. Lu CD, Altieri DC and Tanigawa N: Expression of a novel antiapoptosis gene, survivin, correlated with tumor cell apoptosis and p53 accumulation in gastric carcinomas. Cancer Res 58: 1808-1812, 1998.

19. Nakamura M, Tsuji N, Asanuma K, et al: Survivin as a predictor of cis-diamminedichloroplatinum sensitivity in gastric cancer patients. Cancer Sci 95: 44-51, 2004.

20. Kawasaki H, Altieri DC, Lu CD, Toyoda M, Tenjo T and Tanigawa N: Inhibition of apoptosis by survivin predicts shorter survival rates in colorectal cancer. Cancer Res 58: 5071-5074, 1998.

21. Sarela AI, Macadam RC, Farmery SM, Markham AF and Guillou PJ: Expression of the antiapoptosis gene, survivin, predicts death from recurrent colorectal carcinoma. Gut 46: $645-650,2000$

22. Satoh K, Kaneko K, Hirota M, Masamune A, Satoh A and Shimosegawa T: Expression of survivin is correlated with cance cell apoptosis and is involved in the development of human pancreatic duct cell tumors. Cancer 92: 271-278, 2001.

23. Ikeguchi M, Ueta T, Yamane $\mathrm{Y}$, Hirooka $\mathrm{Y}$ and Kaibara N: Inducible nitric oxide synthase and survivin messenger RNA expression in hepatocellular carcinoma. Clin Cancer Res 8 $3131-3136,2002$
24. Saitoh Y, Yaginuma Y and Ishikawa M: Analysis of Bcl-2, Bax and Survivin genes in uterine cancer. Int J Oncol 15: 137-141, 1999.

25. Yoshida H, Ishiko O, Sumi T, Matsumoto Y and Ogita S: Survivin, bcl-2 and matrix metalloproteinase-2 enhance progression of clear cell- and serous-type ovarian carcinomas. Int J Oncol 19: 537-542, 2001.

26. Adida C, Recher C, Raffoux E, et al: Expression and prognostic significance of survivin in de novo acute myeloid leukaemia. $\mathrm{Br}$ J Haematol 111: 196-203, 2000.

27. Wagner M, Schmelz K, Wuchter C, Ludwig WD, Dorken B and Tamm I: In vivo expression of survivin and its splice variant survivin-2B: impact on clinical outcome in acute myeloid leukemia. Int J Cancer 119: 1291-1297, 2006.

28. Kuribayashi K, Krigsfeld G, Wang W, et al: TNFSF10 (TRAIL), a p53 target gene that mediates p53-dependent cell death. Cancer Biol Ther 7: 2034-2038, 2008.

29. Kuribayashi K and El-Deiry WS: Regulation of programmed cell death by the p53 pathway. Adv Exp Med Biol 615: 201-221, 2008.

30. Pennati M, Folini $\mathrm{M}$ and Zaffaroni N: Targeting survivin in cancer therapy: fulfilled promises and open questions. Carcinogenesis 28: 1133-1139, 2007.

31. O'Connor DS, Wall NR, Porter AC and Altieri DC: A p34(cdc2) survival checkpoint in cancer. Cancer Cell 2: 43-54, 2002.

32. Pennati M, Campbell AJ, Curto M, et al: Potentiation of paclitaxel-induced apoptosis by the novel cyclin-dependent kinase inhibitor NU6140: a possible role for survivin down-regulation. Mol Cancer Ther 4: 1328-1337, 2005.

33. Chang CC, Heller JD, Kuo J and Huang RC: Tetra-O-methyl nordihydroguaiaretic acid induces growth arrest and cellular apoptosis by inhibiting $\mathrm{Cdc} 2$ and survivin expression. Proc Natl Acad Sci USA 101: 13239-13244, 2004

34. Plescia J, Salz W, Xia F, et al: Rational design of shepherdin, a novel anticancer agent. Cancer Cell 7: 457-468, 2005.

35. Kaneko R, Tsuji N, Asanuma K, Tanabe H, Kobayashi D and Watanabe N: Survivin down-regulation plays a crucial role in 3-hydroxy-3-methylglutaryl coenzyme A reductase inhibitorinduced apoptosis in cancer. J Biol Chem 282: 19273-19281, 2007.

36. Tang Y, Zhao DY, Elliott S, et al: Epigallocatechin-3 gallate induces growth inhibition and apoptosis in human breast cancer cells through survivin suppression. Int J Oncol 31: 705-711, 2007.

37. Biran A, Brownstein M, Haklai R and Kloog Y: Downregulation of survivin and aurora A by histone deacetylase and RAS inhibitors: A new drug combination for cancer therapy. Int $\mathrm{J}$ Cancer 128: 691-701, 2011.

38. Karin M: Nuclear factor-kappaB in cancer development and progression. Nature 441: 431-436, 2006.

39. Irwin MS and Kaelin WG Jr: Role of the newer p53 family proteins in malignancy. Apoptosis 6: 17-29, 2001.

40. Shammas MA, Neri P, Koley H, et al: Specific killing of multiple myeloma cells by (-)-epigallocatechin-3-gallate extracted from green tea: biologic activity and therapeutic implications. Blood 108: 2804-2810, 2006.

41. Mirza A, McGuirk M, Hockenberry TN, et al: Human survivin is negatively regulated by wild-type p53 and participates in p53-dependent apoptotic pathway. Oncogene 21: 2613-2622, 2002.

42. Hoffman WH, Biade S, Zilfou JT, Chen J and Murphy M: Transcriptional repression of the anti-apoptotic survivin gene by wild type p53. J Biol Chem 277: 3247-3257, 2002.

43. Yang A and McKeon F: P63 and P73: P53 mimics, menaces and more. Nat Rev Mol Cell Biol 1: 199-207, 2000 